\title{
How to teach safe landing after the jump? The use of biofeedback to minimize the shock forces generated in elements of modern dance
}

\author{
JOANNA GORWA ${ }^{1 *}$, ROBERT MICHNIK ${ }^{2}$, KATARZYNA NOWAKOWSKA-LIPIEC $^{2}$ \\ ${ }^{1}$ Department of Biomechanics, Faculty of Sport Sciences, Poznan University of Physical Education, Poznań, Poland. \\ ${ }^{2}$ Department of Biomechatronics, Faculty of Biomedical Engineering, Silesian University of Technology, Zabrze, Poland.
}

\begin{abstract}
Purpose: The aim of the study was to assess the possible use of biofeedback (information on the course and values of ground reaction forces (GRF) during landing following the performance of a dance evolution) for training minimising impact loads after a jump in modern dance. Methods: The tests involved the analysis of a total of 60 expressive elements of modern dance performed by 5 soloists. The tests involved the recording of the vertical component of GRF $\left(\mathrm{GRF}_{\mathrm{z}}\right)$ vector using Kistler platform in the landing phase following the performance of modern dance jumps. The dancers performed the above-named jumps three times in successive tests: a reference test (without biofeedback) and the next two tests with biofeedback, after the obtainment of information about the vertical value of GRF. After each performance, the dancers watched a course of GRF and films showing the recorded landing phase. Results: Applying of a proposed didactic laboratory session led to: extension of contact time and of time preceding the obtainment of the maximum value of $\mathrm{GRF}_{\mathrm{z}}$, reduction of the maximum values of the vertical components of the GRF, reduction of the loading rate of the ground reaction force, increase of an impulse of the vertical component of GRF in the entire stance phase and in the shock absorption phase. Conclusions: Proposed didactic laboratory session with biofeedback may result in the change of the post-jump shock absorption technique.
\end{abstract}

Key words: ground reaction force, modern dance, jump, load, dancer's workday

\section{Introduction}

Modern dance developed in the 1920s. Governed by the principles of a specific technique, it evolved in the USA in the years 1930-1950 using elements of African and Indian folklore as well as movements of Japanese Butoh dance [21]. Based on the idea of classical dance, modern dance is free from the stiff principles of the former, giving particular emphasis on showing of dancer's emotions [9], [21]. In modern dance, the dancer is, to a large extent, free in the creation and interpretation of movements, where distance and moving in space are of particular importance [15].

In terms of technique, modern dance combines powerful, yet controlled, work of lower limbs, typi- cal for classical dance [11], [14] with modernity, focused on the centre of gravity, work with one's breathing and "awareness of the body" [9]. In addition, modern dance also involves the relaxation of contraction, work close to and directly on the floor, falls and returns as well as improvised elements [21]. Modern dance is also characterised by frequent changes in rhythm, speed and direction, unpredictable for spectators. The technique of modern dance is perceived as a constantly evolving lifelong process [9].

Most expressive movement-related tasks of modern dancers involve jumps. Previous research revealed that some of the modern dance jumps, particularly in the landing phase (during eccentric muscular work connected with shock absorption) generate significant

\footnotetext{
* Corresponding author: Joanna Gorwa, Department of Biomechanics, Faculty of Sport Sciences, Poznan University of Physical Education, ul. Królowej Jadwigi 27/39,61-871 Poznan, Poland. E-mail: gorwa@awf.poznan.pl

Received: March 15th, 2021

Accepted for publication: May 28th, 2021
} 
values of the vertical component of the ground reaction force, reaching up to $5 \mathrm{BW}$ [BW - body weight] [17]. According to Liederbach [22], landing on one limb after a jump is responsible for an injury in as many as $92 \%$ cases of all dance injuries. On average, the daily training of a professional dancer working in a dance theatre amounts to as many as 10 hours, including performances. The weekly workload amounts to approximately 60 hours [5], [17].

Significant training loads, performance tours and the overloaded annual schedule of performances make this professional group highly susceptible to injuries [9], [5]. It seems that reference publications on modern dancers inform about injuries in this style of dance quite exhaustively [7], [11], [31]. Special preventive programmes developed for this occupational group [7], [11] are based on the improved flow of information and quick medical reaction [2], [6], [25], mental education of dancers, improvements in the dance technique [11] as well as complex intervention, including internal medical and therapeutic services [7]. Many artists specialising in modern dance apply interventionist training, involving the use of biomechanical tools such as mastering the balance control [20], [28], plyometric supplemental training on vertical jump height [8] and supplemental training on fitness [3]. Obviously, improper dance technique contributes to injuries [1], [4], [6], [27].

However, scientific reference publications lack information on practical training providing the possible minimisation of loads during landing. Among four risk factors, Bronner and Bauer [6] find dance technique and motor-control as strict predictors of injuries in modern dancers and prove that artists with a better dance technique are exposed to lower post-traumatic injuries.

According to Liederbach [22], dancers are promoted to the professional level only after working out the virtuoso jump and balance technique, the achievement of which takes years of work. It seems important to appropriately prepare dancers in terms of motor activity and turn their particular attention to the level of loads they are expose to during exercises. The time necessary to reach the aforesaid level may probably be reduced using the potential of a biomechanical laboratory in the form of motion analysis systems and dynamometric platforms.

The work aimed to assess the possible use of biofeedback (information on the course and values of vertical component of the ground reaction force (GRF) during landing following the performance of a dance evolution) for training minimising impact loads after a jump in modern dance.
The Authors have formulated a hypothesis that with the use of biofeedback, soloist dancers, i.e., masters of technique representing the highest dance level, are capable of reducing the value of the vertical component of the ground reaction force and the value of the loading rate of the GRF $\left(L R_{\mathrm{GRFz}}\right)$, without compromising the aesthetics and correctness of choreographic elements. We expect that the reduction of impact loads primarily may result from the extension of contact time and the extension time preceding the obtainment of maximum value GRF.

\section{Materials and methods}

\subsection{Experiment design}

The first step was to produce a list of first modern dance soloists in Poznań (Poland) and planning a meeting with the dancers. Before the research in the Poznan Ballet Dance Theater (Poland), an informative meeting was held, during which the purpose of the research, the way it was conducted, the research apparatus, as well as the inclusion criteria were explained. The inclusion criteria for the studies were as follows: adult modern dancers at the age of 18-40, who had been working full-time employee at a modern dance theater and did not do any other job, who had a total career time (the years between starting ballet school education and the day of examination) over 8 years, a professional career time (years in decimal notation between the date of starting occupational activity in a ballet group and the day of examination) over 2 years. All of the artists were healthy without any injuries within the last six months. 11 soloists (first dancers) of the Poznan Ballet Dance Theater were invited to participate in the research, and 5 soloists applied for the research.

All of the artists submitted their written consent to participate in the tests. The study was approved by the Bioethical Committee at the Poznan University of Medical Sciences, Poland (decision no. 796/09).

Pilot studies have been carried out to determine the minimum sample size. Then the actual experiment was carried out. The tests performed in a biomechanical-kinesiological laboratory were attended by a choreographer and a classical dance pedagogue, supervising the technical correctness of jumps as well as an OHSE specialist (Occupational Health, Safety \& Environmental specialist), coordinating the safety of the test participants. 


\subsection{Participants}

The study group consisted of 5 first modern soloists -3 males and 2 females (Table 1). The artists represented the highest level of dance technique and were worldwide known masters of modern dance. plying a didactic laboratory session suggested by the Authors. The purpose of the session was to minimise impact forces generated during landing.

The artists performed the jumps: Skip, Stag jump, Flat pas de chat and Sisonne overt parallel, in three successive tests:

- test no. 1 - a reference test, without biofeedback;

Table 1. Characteristics of the group of dancers subjected to tests

\begin{tabular}{|c|c|c|c|c|c|c|}
\hline $\begin{array}{c}\text { Symbol } \\
\text { of the test dancer }\end{array}$ & $\begin{array}{c}\text { Sex } \\
\text { (F-female, } \\
\text { M-male) }\end{array}$ & $\begin{array}{c}\text { Age } \\
{[\text { years }]}\end{array}$ & $\begin{array}{c}\text { Body mass } \\
{[\mathrm{kg}]}\end{array}$ & $\begin{array}{c}\text { Body } \\
\text { height } \\
{[\mathrm{m}]}\end{array}$ & $\begin{array}{c}\text { Professional } \\
\text { career } \\
{[\text { years] }}\end{array}$ & $\begin{array}{c}\text { Total } \\
\text { career } \\
\text { [years] }\end{array}$ \\
\hline D1 & M & 29 & 71 & 1.81 & 10 & 19 \\
\hline D2 & F & 27 & 51 & 1.52 & 9 & 17 \\
\hline D3 & F & 21 & 50 & 1.65 & 2 & 11 \\
\hline D4 & M & 27 & 81 & 1.81 & 8 & 8 \\
\hline D5 & M & 27 & 69 & 1.74 & 8 & 17 \\
\hline
\end{tabular}

\subsection{Measurement equipment}

The tests involved the recording of GRF in the landing phase following the performance of: Skip, Stag jump, Flat pas de chat and Sisonne overt parallel. The measurements of vertical component of GRF $\left(\mathrm{GRF}_{\mathrm{z}}\right)$ and other variables (presented below) in time were performed using a KISTLER 9261A triaxial piezoelectric platform (Kistler Group, Winterthur, Switzerland, sampling rate: $1000 \mathrm{~Hz}$ ) combined with a PC via a 12-bit and 16-channel AMBEX analogue card. The movements of the test participants were recorded using four digital cameras (Basler AG, Germany) having a sampling rate of $200 \mathrm{~Hz}$. Data were collected as previously described in Gorwa et al. [15]. Specifically, the variables from the platforms were analyzed.

\subsection{Measurement protocol}

The tests involved the analysis of a total of 60 expressive elements of modern dance: 4 types of jumps: Skip, Stag jump, Flat pas de chat and Sisonne overt parallel. The selection of the analyzed elements was consulted with the choreographer. The condition for qualifying a given jump for the experiment was the possibility of classifying it among the elements of this dance style and its popularity in repertoires in dance modern theatres.

The tests involved the recording of the vertical values of ground reaction forces. Measurements involving the use of the platform were performed ap-
- test no. 2 - a test with biofeedback, after the obtainment of information about the vertical value of GRF with the recommendation "more carefully" (try to reduce the value of impact force);

- test no. 3 - a test with biofeedback, after the obtainment of information about the vertical value of GRF with recommendation "even more carefully".

Before a didactic laboratory session, each of the dancers did a half-hour warm-up.

After each performance, the dancers could watch a visualised course of $\mathrm{GRF}_{\mathrm{z}}$ in $\mathrm{BW}$ as an image projected by a video beamer (Fig. 1) and films showing the recorded landing phase after the performance of a dance evolution. There were short breaks (about 3 minutes) between the tests of a given jump, during which the above-described biofeedback was carried out. Between the examined types of jumps, 10-minute breaks were taken into account.

Biomechanical tests results were analysed by a biomechanical specialist with 20 -years' experience. And the correctness and aesthetics of performance were evaluated by the pedagogue and choreographer. The collected information from specialists was passed on to the performer and was part of the didactic laboratory session.

The courses of the vertical component of GRF recorded during the tests were subjected to the analysis which aimed to determine the following variables:

- $\operatorname{maxGRF}_{z}[\mathrm{BW}]$ - a maximum value of the vertical variable of the ground reaction force referred to the weight of a given person subjected to the test; 
- $t[\mathrm{~s}]$ - the contact time - the time from the first foot contact with the ground to the moment the foot off the ground;

- $t_{\text {maxGRFz }}[\mathrm{s}]$ - the time from first foot contact with the ground to the moment of reaching the $\operatorname{maxGRF}_{z}$ (Fig. 1),

- $L R_{\mathrm{GRFz}}[\mathrm{BW} / \mathrm{s}]$ - loading rate of the ground reaction force referred to the weight of a given person subjected to the test [33];

$$
L R_{\mathrm{GRF}_{\mathrm{z}}}=\frac{\max \mathrm{GRF}_{\mathrm{z}}}{t_{\max \mathrm{GRF}_{\mathrm{z}}}}
$$

- $J$ [BW-s] - a impulse of the vertical component of $\mathrm{GRF}_{\mathrm{z}}$ in the entire stance phase referred to BW;

$$
J=\int_{0}^{t} \mathrm{GRF}_{\mathrm{z}}
$$

- $J_{\operatorname{maxGRF}}[\mathrm{BW} \cdot \mathrm{s}]$ - a impulse of the vertical component of GRF in the shock absorption phase (from 0 to $\operatorname{maxGRF} F_{z}$ ) referred to $\mathrm{BW}$.

$$
J=\int_{0}^{t_{\max G R F_{z}}} \mathrm{GRF}_{\mathrm{z}}
$$

\subsection{Statistics}

The sample size was a priori estimated based on the values of the vertical component of ground reaction forces from earlier pilot studies and the assumption that the effect size will be at least medium $(d=0.5$; Cohen's $d$, a measure of effect which indicates the number of standard deviations between two means). Using an $\alpha$-level of 0.05 and a statistical power $(1-\beta$; $\beta$ - the probability of a type II error) of 0.80 , it was calculated that a single sample size of 5 participants would be needed to detect significant differences in reducing $\operatorname{maxGRF}_{z}\left(\mathrm{G}^{*}\right.$ Power, Heinrich-Heine-Universität Düsseldorf, Germany).

The normality of the distribution of variables subjected to the analysis was verified using the ShapiroWilk test. The differences of the analyzed variables for individual jumps obtained in the biofeedback tests and in the reference test were checked by the Student's $t$-test for dependent samples or the Wilcoxon test (depending on the normal distribution). The occurrence of differences between the results of the analyzed variables obtained jointly for all jumps in subsequent trials (test no. 1 , no. 2 , no. 3) was checked

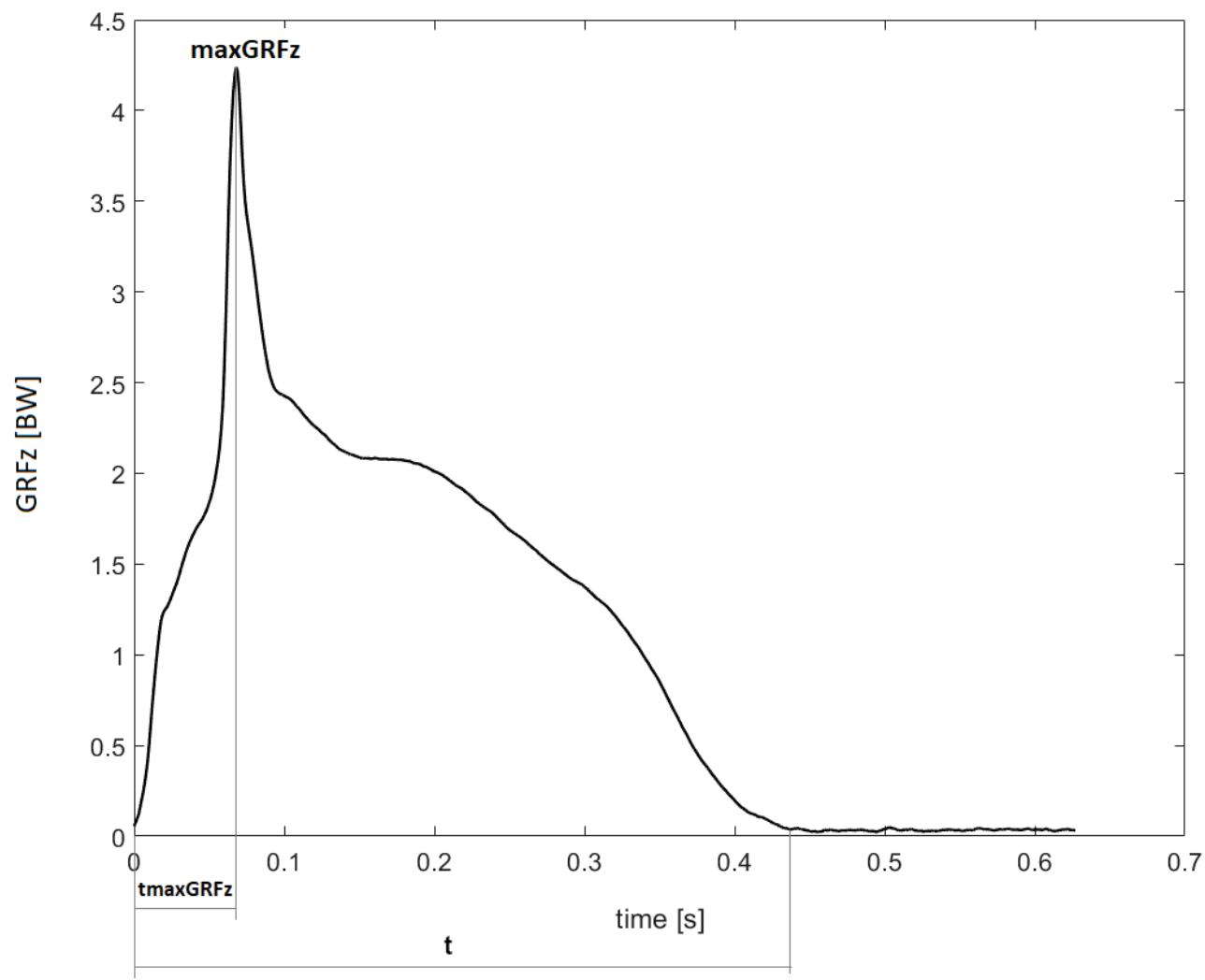

Fig. 1. Vertical component of the ground reaction force with analysed variables (an example curve obtained for one of the dancers). Legend: $\operatorname{maxGRF}_{\mathrm{z}}$ - a maximum value of the vertical component of the ground reaction force referred to the weight of a given person subjected to the test; $t$ - the contact time - the time from the first foot contact with the ground to the moment the foot off the ground; $t_{\text {maxGRF}_{\mathrm{z}}}$ - the time from first foot contact with the ground to the moment of reaching the maxGRF 
by performing the Friedman ANOVA/ANOVA test. If the assumptions for the ANOVA (normality of distribution, homogeneity of variance) were not met, a nonparametric ANOVA Friedman test for dependent samples was performed. The significance level adopted in the statistical analyses was $\alpha=0.05$. The calculations were performed using the PQStat 1.8 programme developed by PQStat Software.

\section{Results}

The didactic laboratory session proposed by the Authors, minimising dancers' impact forces satisfied the Authors' expectations.

In Table 2, values of $\operatorname{maxGRF}$ and $L R_{\mathrm{GRFz}}$ in subsequent tests of the dancers are presented. The grey colour indicates the tests with biofeedback, for which a minimum $10 \%$ decrease in the value of $\operatorname{maxGRF}_{z}$ in relation to the reference test was re- corded (test no. 1). In Figure 2a-b, the mean values of $\operatorname{maxGRF} F_{z}$ and $L R_{\mathrm{GRFz}}$ obtained in relation to the entire group of dancers in subsequent tests are presented.

The maximum values of $\mathrm{GRF}_{\mathrm{z}}$ in relation to analysed dance evolutions were restricted within the range of $1.7 \mathrm{BW}$ to $5.47 \mathrm{BW}$. The mean values of $\operatorname{maxGRF}_{\mathrm{z}}$ in test 1 recorded in relation to Skip, Sisonne overt parallel and Flat pas de chat were similar and amounted to approximately $3.5 \mathrm{BW}$. A slightly lower mean value of 2.66 BW was recorded in relation to Sisonne overt parallel: $2.66 \mathrm{BW}$.

In Table 3, the results of the impulse of the vertical component of GRF in the entire stance phase $J$ and in the shock absorption phase $J_{\operatorname{maxGRFz}}$ are presented. In Figure $2 \mathrm{c}-\mathrm{d}$, obtained mean values $J$ and $J_{\operatorname{maxGRF}}$ in relation to the entire group of dancers are presented.

In Table 4, the results of time variables, i.e., $t$ and $t_{\operatorname{maxGRF}}$, obtained by the dancers are listed. The mean values of these variables obtained for the entire group of dancers are presented in Fig. 2e-f.

Table 2. Values of maxGRF $F_{\mathrm{z}}$ and $L R_{\mathrm{GRFz}}$

\begin{tabular}{|c|c|c|c|c|c|c|c|}
\hline \multirow{2}{*}{$\begin{array}{l}\text { Name } \\
\text { of jump }\end{array}$} & \multirow{2}{*}{$\begin{array}{c}\text { Symbol of the } \\
\text { test dancer }\end{array}$} & \multicolumn{2}{|c|}{ Test no. 1} & \multicolumn{2}{|c|}{ Test no. 2} & \multicolumn{2}{|c|}{ Test no. 3} \\
\hline & & $\begin{array}{c}\operatorname{maxGRF}_{z} \\
{[\mathrm{BW}]}\end{array}$ & $\begin{array}{l}L R_{\mathrm{GRFz}} \\
{[\mathrm{BW} / \mathrm{s}]}\end{array}$ & $\begin{array}{c}\operatorname{maxGRF}_{\mathrm{z}} \\
{[\mathrm{BW}]}\end{array}$ & $\begin{array}{l}L R_{\mathrm{GRFz}} \\
{[\mathrm{BW} / \mathrm{s}]}\end{array}$ & $\begin{array}{c}\operatorname{maxGRF}_{z} \\
{[\mathrm{BW}]}\end{array}$ & $\begin{array}{l}L R_{\mathrm{GRFz}} \\
{[\mathrm{BW} / \mathrm{s}]}\end{array}$ \\
\hline \multirow{5}{*}{ Skip } & D1 & 3.17 & 17.39 & 3.26 & 16.11 & 3.24 & 17.69 \\
\hline & D2 & 3.51 & 29.21 & 2.04 & 17.29 & 2.13 & 21.72 \\
\hline & D3 & 3.63 & 54.12 & 2.53 & 14.87 & 5.02 & 74.90 \\
\hline & $\mathrm{D} 4$ & 3.70 & 37.80 & 2.48 & 12.93 & 3.16 & 33.27 \\
\hline & D5 & 3.09 & 21.17 & 2.89 & 20.05 & 2.99 & 21.81 \\
\hline \multirow{5}{*}{$\begin{array}{l}\text { Sisonne overt } \\
\text { parallel }\end{array}$} & D1 & 2.37 & 16.72 & 2.20 & 10.34 & 1.49 & 5.65 \\
\hline & $\mathrm{D} 2$ & 1.70 & 26.19 & 1.75 & 29.21 & 1.90 & 11.53 \\
\hline & D3 & 2.39 & 22.53 & 2.50 & 22.55 & 3.24 & 27.72 \\
\hline & D4 & 3.10 & 24.78 & 5.08 & 56.49 & 4.48 & 43.05 \\
\hline & D5 & 3.72 & 44.28 & 3.06 & 28.36 & 2.29 & 13.21 \\
\hline \multirow{5}{*}{ Stag jump } & D1 & 2.71 & 25.78 & 2.46 & 15.79 & 2.19 & 13.08 \\
\hline & D2 & 2.72 & 181.10 & 2.47 & 30.07 & 2.59 & 14.98 \\
\hline & D3 & 5.24 & 91.85 & 3.35 & 25.54 & 3.36 & 36.90 \\
\hline & D4 & 3.07 & 25.20 & 3.00 & 27.73 & 2.52 & 23.14 \\
\hline & D5 & 3.69 & 52.00 & 2.51 & 29.16 & 3.01 & 37.59 \\
\hline \multirow{5}{*}{ Flat pas de chat } & D1 & 2.17 & 24.91 & 5.22 & 111.16 & 2.21 & 17.84 \\
\hline & D2 & 5.47 & 151.96 & 3.93 & 95.87 & 3.09 & 57.26 \\
\hline & D3 & 5.01 & 161.46 & 5.72 & 168.25 & 6.33 & 137.68 \\
\hline & D4 & 2.37 & 38.27 & 5.17 & 152.08 & 1.78 & 10.80 \\
\hline & D5 & 2.69 & 39.02 & 2.34 & 15.01 & 3.17 & 38.70 \\
\hline
\end{tabular}

$\operatorname{maxGRF}_{\mathrm{z}}-$ a maximum value of the vertical variable of the ground reaction force referred to the weight of a given person subjected to the test; $L R_{\mathrm{GRFz}}$ - loading rate of the ground reaction force referred to the weight of a given person subjected to the test; test no. 1 - a reference test, without biofeedback; test no. 2 - a test with biofeedback, after the obtainment of information about the vertical value of GRF with the recommendation "more carefully"; test no. 3 - a test with biofeedback, after the obtainment of information about the vertical value of GRF with recommendation "even more carefully"; the grey colour indicates the tests with biofeedback, for which a minimum $10 \%$ decrease in the value of maxGRF $F_{z}$ in relation to the reference test was recorded (test no. 1). 
Table 3. Impulses of GRF: $J$, $J_{\operatorname{maxGRF}}$

\begin{tabular}{|c|c|c|c|c|c|c|c|}
\hline \multirow{2}{*}{$\begin{array}{l}\text { Name } \\
\text { of jump }\end{array}$} & \multirow{2}{*}{$\begin{array}{c}\text { Symbol } \\
\text { of the test } \\
\text { dancer }\end{array}$} & \multicolumn{2}{|c|}{ Test no. 1} & \multicolumn{2}{|c|}{ Test no. 2} & \multicolumn{2}{|c|}{ Test no. 3} \\
\hline & & $\begin{array}{c}J \\
{[\mathrm{BW} \cdot \mathrm{s}]}\end{array}$ & $\begin{array}{c}J_{\operatorname{maxGRFz}} \\
{[\mathrm{BW} \cdot \mathrm{s}]}\end{array}$ & $\begin{array}{c}J \\
{[\mathrm{BW} \cdot \mathrm{s}]}\end{array}$ & $\begin{array}{c}J_{\operatorname{maxGRFz}} \\
{[\mathrm{BW} \cdot \mathrm{s}]}\end{array}$ & $\begin{array}{c}J \\
{[\mathrm{BW} \cdot \mathrm{s}]}\end{array}$ & $\begin{array}{c}J_{\operatorname{maxGRFz}} \\
{[\mathrm{BW} \cdot \mathrm{s}]}\end{array}$ \\
\hline \multirow[t]{5}{*}{ Skip } & D1 & 0.61 & 0.34 & 0.59 & 0.34 & 0.65 & 0.33 \\
\hline & D2 & 0.43 & 0.19 & 0.62 & 0.16 & 0.65 & 0.13 \\
\hline & D3 & 0.57 & 0.11 & 0.63 & 0.30 & 0.67 & 0.11 \\
\hline & D4 & 0.62 & 0.16 & 0.71 & 0.34 & 0.72 & 0.15 \\
\hline & D5 & 0.52 & 0.29 & 0.52 & 0.27 & 0.53 & 0.26 \\
\hline \multirow{5}{*}{$\begin{array}{l}\text { Sisonne overt } \\
\text { parallel }\end{array}$} & D1 & 1.01 & 0.16 & 0.85 & 0.21 & 1.03 & 0.30 \\
\hline & D2 & 0.75 & 0.06 & 0.77 & 0.05 & 1.00 & 0.23 \\
\hline & D3 & 0.83 & 0.15 & 0.99 & 0.16 & 1.12 & 0.21 \\
\hline & D4 & 0.59 & 0.17 & 0.77 & 0.13 & 0.73 & 0.16 \\
\hline & D5 & 0.75 & 0.10 & 0.88 & 0.18 & 0.83 & 0.27 \\
\hline \multirow{5}{*}{ Stag jump } & D1 & 0.66 & 0.16 & 0.66 & 0.25 & 0.81 & 0.27 \\
\hline & D2 & 0.65 & 0.01 & 0.65 & 0.17 & 0.52 & 0.35 \\
\hline & D3 & 0.94 & 0.11 & 0.77 & 0.28 & 0.84 & 0.18 \\
\hline & D4 & 0.62 & 0.23 & 0.86 & 0.21 & 0.69 & 0.20 \\
\hline & D5 & 0.84 & 0.12 & 0.58 & 0.13 & 0.69 & 0.13 \\
\hline \multirow{5}{*}{ Flat pas de chat } & D1 & 0.61 & 0.08 & 0.63 & 0.05 & 0.65 & 0.16 \\
\hline & D2 & 0.65 & 0.06 & 0.62 & 0.08 & 0.61 & 0.08 \\
\hline & D3 & 0.72 & 0.05 & 0.99 & 0.05 & 0.68 & 0.06 \\
\hline & D4 & 0.56 & 0.06 & 0.65 & 0.05 & 0.59 & 0.20 \\
\hline & D5 & 0.52 & 0.07 & 0.57 & 0.25 & 0.60 & 0.09 \\
\hline
\end{tabular}

$J-$ a impulse of the vertical component of $\mathrm{GRF}_{\mathrm{z}}$ in the entire stance phase referred to body weight; $J_{\operatorname{maxGRF}}-\mathrm{a}$ impulse of the vertical component of GRF in the shock absorption phase (from 0 to $\operatorname{maxGRF}_{\mathrm{z}}$ ) referred to body weight; test no. 1 - a reference test, without biofeedback; test no. 2 - a test with biofeedback, after the obtainment of information about the vertical value of GRF with the recommendation "more carefully"; test no. 3 - a test with biofeedback, after the obtainment of information about the vertical value of GRF with recommendation "even more carefully".

Table 4. Time parameters: $t$ and $t_{\text {maxGRFz }}$

\begin{tabular}{|c|c|c|c|c|c|c|c|}
\hline \multirow{2}{*}{$\begin{array}{l}\text { Name } \\
\text { of jump }\end{array}$} & \multirow{2}{*}{$\begin{array}{l}\text { Symbol } \\
\text { of the test } \\
\text { dancer }\end{array}$} & \multicolumn{2}{|c|}{ Test no. 1} & \multicolumn{2}{|c|}{ Test no. 2} & \multicolumn{2}{|c|}{ Test no. 3} \\
\hline & & $t[\mathrm{~s}]$ & $t_{\operatorname{maxGRFz}}[\mathrm{s}]$ & $t[\mathrm{~s}]$ & $t_{\operatorname{maxGRFz}}[\mathrm{s}]$ & $t[\mathrm{~s}]$ & $t_{\operatorname{maxGRFz}}[\mathrm{s}]$ \\
\hline \multirow{5}{*}{ Skip } & D1 & 0.33 & 0.18 & 0.34 & 0.20 & 0.35 & 0.18 \\
\hline & D2 & 0.26 & 0.12 & 0.45 & 0.12 & 0.49 & 0.10 \\
\hline & D3 & 0.29 & 0.07 & 0.40 & 0.17 & 0.43 & 0.07 \\
\hline & D4 & 0.32 & 0.10 & 0.44 & 0.19 & 0.44 & 0.10 \\
\hline & D5 & 0.30 & 0.15 & 0.32 & 0.14 & 0.31 & 0.14 \\
\hline \multirow{5}{*}{$\begin{array}{l}\text { Sisonne } \\
\text { overt parallel }\end{array}$} & D1 & 0.85 & 0.14 & 0.75 & 0.21 & 0.90 & 0.26 \\
\hline & $\mathrm{D} 2$ & 0.65 & 0.07 & 0.66 & 0.06 & 0.88 & 0.17 \\
\hline & D3 & 0.58 & 0.11 & 0.71 & 0.11 & 0.84 & 0.12 \\
\hline & D4 & 0.37 & 0.13 & 0.50 & 0.09 & 0.45 & 0.10 \\
\hline & D5 & 0.51 & 0.08 & 0.57 & 0.11 & 0.61 & 0.17 \\
\hline \multirow{5}{*}{ Stag jump } & D1 & 0.43 & 0.11 & 0.44 & 0.16 & 0.58 & 0.17 \\
\hline & D2 & 0.36 & 0.02 & 0.35 & 0.08 & 0.29 & 0.17 \\
\hline & D3 & 0.68 & 0.06 & 0.48 & 0.13 & 0.59 & 0.09 \\
\hline & D4 & 0.32 & 0.12 & 0.53 & 0.11 & 0.40 & 0.11 \\
\hline & D5 & 0.48 & 0.07 & 0.36 & 0.09 & 0.48 & 0.08 \\
\hline \multirow{5}{*}{ Flat pas de chat } & D1 & 0.58 & 0.09 & 0.56 & 0.05 & 0.61 & 0.12 \\
\hline & D2 & 0.53 & 0.04 & 0.45 & 0.04 & 0.52 & 0.05 \\
\hline & D3 & 0.66 & 0.03 & 1.15 & 0.03 & 0.37 & 0.05 \\
\hline & D4 & 0.47 & 0.06 & 0.53 & 0.03 & 0.50 & 0.17 \\
\hline & D5 & 0.34 & 0.07 & 0.37 & 0.16 & 0.38 & 0.08 \\
\hline
\end{tabular}

$t$ - the contact time - the time from the first foot contact with the ground to the moment the foot off the ground; $t_{\operatorname{maxGRF}}-$ the time from first foot contact with the ground to the moment of reaching the maxGRF $F_{z}$; test no. 1 - a reference test, without biofeedback; test no. 2 - a test with biofeedback, after the obtainment of information about the vertical value of GRF with the recommendation "more carefully"; test no. 3 - a test with biofeedback, after the obtainment of information about the vertical value of GRF with recommendation "even more carefully". 

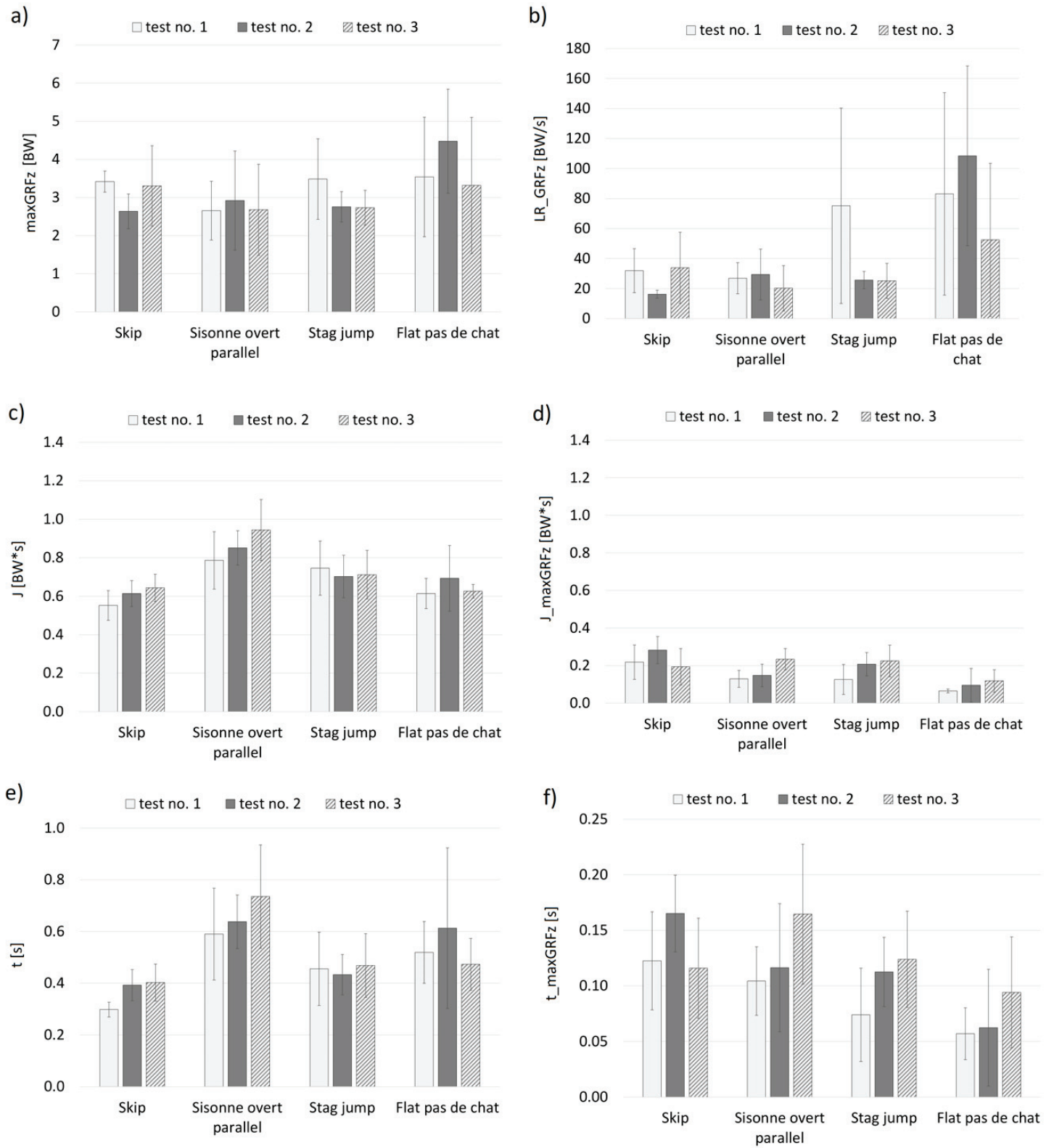

Fig. 2. Mean values and standard deviations of a) $\operatorname{maxGRF}_{\mathrm{z}}$, b) $L R_{\mathrm{GRFz}}$, c) $J$, d) $J_{\operatorname{maxGRF}}$, e) $t$ and f) $t_{\operatorname{maxGRF}}$ obtained in relation to the entire group of dancers in subsequent tests.

Legend: $\operatorname{maxGRF}_{\mathrm{z}}$ - a maximum value of the vertical variable of the ground reaction force referred to the weight of a given person subjected to the test; $L R_{\mathrm{GRFz}}$ - loading rate of the ground reaction force referred to the weight of a given person subjected to the test; $J$ - a impulse of the vertical component of $\mathrm{GRF}_{\mathrm{z}}$ in the entire stance phase referred to body weight; $J_{\operatorname{maxGRFz}}-$ a impulse of the vertical component of GRF in the shock absorption phase (from 0 to maxGRF $\mathrm{z}_{\mathrm{z}}$ ) referred to body weight; $t$ - the contact time - the time from the first foot contact with the ground to the moment the foot off the ground; $t_{\operatorname{maxGRF}}-$ the time from first foot contact with the ground to the moment of reaching the $\operatorname{maxGRF}_{z}$; test no. 1 - a reference test, without biofeedback; test no. 2 - a test with biofeedback, after the obtainment of information about the vertical value of GRF with the recommendation "more carefully"; test no. 3 - a test with biofeedback, after the obtainment of information about the vertical value of GRF with recommendation "even more carefully"

For individual jumps, the Shapiro-Wilk tests showed a normal distribution for most of the analyzed variables in subsequent tests. The normality of the distribution was not noted for: $L R_{\mathrm{GRFz}}$ for Flat pas de chat in test no. 1 , for $L R_{\mathrm{GRFz}}$ for Skip and maxGRF $, J, J_{\operatorname{maxGRFz}}$, $t_{\operatorname{maxGRF}}$ for Flat pas de chat in test no. 2, and for $L R_{\mathrm{GRF}}$ for Skip in test no. 3. However, when analyz- ing the results jointly for all jumps, the Shapiro-Wilk tests performed did not show a normal distribution for: $L R_{\mathrm{GRFz}}$ in test no. $1, t, \operatorname{maxGRF}_{\mathrm{z}}, L R_{\mathrm{GRFz}}$ in test no. 2 , and $\operatorname{maxGRF}_{\mathrm{z}}, L R_{\mathrm{GRFz}}, J$ in test no. 3. Analysing variable values separately in relation to each dance evolution revealed that statistically relevant differences were only present in the results obtained for 
Table 5. Statistical test results

\begin{tabular}{|c|c|c|c|c|c|c|}
\hline & \multicolumn{6}{|c|}{$\begin{array}{c}\text { Test no. } 1 \text { vs. Test no. } 2 \text { vs. Test no. } 3 \\
\text { ( } p \text {-value; ANOVA/Friedman ANOVA test) }\end{array}$} \\
\hline & $\operatorname{maxGRF}_{\mathrm{z}}$ & $L R_{\mathrm{GRFz}}$ & $J$ & $J_{\operatorname{maxGRFz}}$ & $t$ & $t_{\operatorname{maxGRFz}}$ \\
\hline all kinds of jumps together & 0.349 & $\underline{0.074}$ & $\underline{0.058}$ & $0.024^{*}$ & $\underline{0.026^{*}}$ & $0.018^{*}$ \\
\hline \multirow[t]{2}{*}{ Name of jump } & \multicolumn{6}{|c|}{$\begin{array}{c}\text { Test no. } 1 \text { vs Test no. } 2 \\
(p \text {-value; Student's } t \text { or Wilcoxon test results) }\end{array}$} \\
\hline & $\operatorname{maxGRF}_{\mathrm{z}}$ & $L R_{\mathrm{GRFz}}$ & $J$ & $J_{\operatorname{maxGRFz}}$ & $t$ & $t_{\text {maxGRFz }}$ \\
\hline Skip & 0.062 & 0.099 & 0.177 & 0.258 & 0.055 & 0.140 \\
\hline Sisonne overt parallel & 0.589 & 0.771 & 0.344 & 0.411 & 0.317 & 0.532 \\
\hline Stag jump & 0.105 & 0.151 & 0.645 & 0.103 & 0.081 & 0.764 \\
\hline Flat pas de chat & 0.352 & 0.477 & $\underline{0.196}$ & $\underline{0.478}$ & 0.407 & $\underline{0.819}$ \\
\hline \multirow[t]{2}{*}{ Name of jump } & \multicolumn{6}{|c|}{$\begin{array}{c}\text { Test no. } 1 \text { vs Test no. } 3 \\
\text { ( } p \text {-value; Student's } t \text { or Wilcoxon test results) }\end{array}$} \\
\hline & $\operatorname{maxGRF}_{\mathrm{z}}$ & $L R_{\mathrm{GRFz}}$ & $J$ & $J_{\operatorname{maxGRFz}}$ & $t$ & $t_{\operatorname{maxGRFz}}$ \\
\hline Skip & 0.817 & $\underline{0.715}$ & 0.062 & 0.099 & 0.064 & 0.193 \\
\hline Sisonne overt parallel & 0.966 & 0.476 & $0.038 *$ & $0.039 *$ & $0.026^{*}$ & 0.095 \\
\hline Stag jump & 0.064 & 0.175 & 0.599 & 0.193 & 0.786 & 0.168 \\
\hline Flat pas de chat & 0.738 & $\underline{0.142}$ & 0.657 & 0.104 & 0.505 & 0.094 \\
\hline
\end{tabular}

* $p \leq 0.05$ - significant difference; the results for the parametric tests (i.e., ANOVA test and Student's $t$-test) are not underlined, the results for the nonparametric tests (i.e., Friedman ANOVA test and Wilcoxon test) are underlined; $\operatorname{maxGRF}_{\mathrm{z}}$ - a maximum value of the vertical variable of the ground reaction force referred to the weight of a given person subjected to the test; $L R_{\mathrm{GRFz}}$ - loading rate of the ground reaction force referred to the weight of a given person subjected to the test; $J$-a impulse of the vertical component of $\mathrm{GRF}_{\mathrm{z}}$ in the entire stance phase referred to body weight; $J_{\text {maxGRFz }}-$ a impulse of the vertical component of GRF in the shock absorption phase (from 0 to $\operatorname{maxGRF}_{\mathrm{z}}$ ) referred to body weight; $t$ - the contact time - the time from the first foot contact with the ground to the moment the foot off the ground; $t_{\mathrm{maxGRF}}$ - the time from first foot contact with the ground to the moment of reaching the $\operatorname{maxGRF}_{\mathrm{z}}$; test no. 1 - a reference test, without biofeedback; test no. 2 - a test with biofeedback, after the obtainment of information about the vertical value of GRF with the recommendation "more carefully"; test no. 3 - a test with biofeedback, after the obtainment of information about the vertical value of GRF with recommendation "even more carefully".

Sisonne overt parallel (Table 5). The differences were observed between the values of $t, J$ and $J_{\operatorname{maxGRFz}}$ obtained in test no. 3 (with biofeedback) and in the reference test. However, it should be taken into consideration that the analyses involved a very small group. In spite of this fact, the power of the tests was restricted within the range of 0.6 to 0.75 . The presence of statistically relevant differences was also verified for variables collected in relation to all $(n=60)$ dance evolutions in test no. $1(n=20), 2(n=20)$ and $3(n=20)$. The ANOVA or Friedman ANOVA tests revealed the existence of statistically relevant differences between the tests in relation to $t, t_{\operatorname{maxGRFz}}$ and $J_{\operatorname{maxGRF}}$ (Table 5).

\section{Discussion}

The didactic laboratory session developed for modern dancers met the Authors' expectations. It appeared that the didactic laboratory session suggestions could affect certain variables important in terms of shock absorption.

The values of $\operatorname{maxGRF}_{\mathrm{z}}$ and $L R_{\mathrm{GRFz}}$ obtained in subsequent tests with biofeedback (Table 2, Fig. 2a-b) indicate that the proposed "minimising training" could bring the expected results.

The analysis of the mean values of $\operatorname{maxGRF}_{z}$ and $L R_{\mathrm{GRFz}}$ obtained in relation to the entire group of dancers revealed a decrease in maximum values of $\mathrm{GRF}_{z}$ and $L R_{\mathrm{GRF}}$ in relation to Stag jump in both tests with biofeedback, decrease in values of maxGRF $F_{\mathrm{z}}$ and $L R_{\mathrm{GRFz}}$ in at least one test with biofeedback in relation to the remaining evolutions, i.e., Skip, Sisonne overt parallel and Flat pas de chat. In relation to individual dancers - maximum decrease in the values of $\operatorname{maxGRF}_{\mathrm{z}}$ amounted to $43 \%$ (above $2 \mathrm{BW}$ ) in relation to the reference test. In relation to $L R_{\mathrm{GRF}}$ it was possible to notice nearly the double decrease of the value. 
Based on the mean values of $\operatorname{maxGRF}_{\mathrm{z}}$, it was possible to observe their decrease in both tests with biofeedback in relation to Stag jump (on average by $0.73 \mathrm{BW}$ in test no. 2 and by $0.75 \mathrm{BW}$ in test no. 3), Skip (on average by $0.78 \mathrm{BW}$ in test no. 2 and by 0.11 BW in test no. 3) and Flat pas de chat (by $0.22 \mathrm{BW}$ in test no. 3) (Fig. 2a-b).

A surprising fact discovered in the research-related tests was that artists' subjective perception (after the performance of a jump) did not always coincide with the results obtained using the dynamometric platform and soloists' attempts to reduce the $\mathrm{GRF}_{\mathrm{z}}$ were not always successful.

In relation to 5 original performances, statistically relevant differences were related to Sissone overt parallel. Differences were observed between the values of variables $t, J$ and $J_{\operatorname{maxGRF}}$ obtained in test no. 3 (with biofeedback) and in the reference test.

Although there were no other statistically relevant differences recorded in relation to the remaining dance evolutions (analysed separately $n=5$ ), the detailed analysis of the values of analysed variables in relation to individual dancers indicated certain tendencies of changes/correlations. The lack of statistically relevant differences undoubtedly resulted from significant standard deviations of results obtained in relation to a small group of tested participants.

Analyzing all jump types together, the ANOVA or Friedman ANOVA tests revealed the existence of statistically relevant differences between the tests in relation to $t, t_{\operatorname{maxGRFz}}$ and $J_{\operatorname{maxGRFz}}$.

In the following sections, possible suggestions and interpretations of the obtained test results are presented.

\subsection{Biomechanical aspects of effective shock absorption}

In the tests, statistically relevant differences were observed only in relation to variables connected with shock absorption time $\left(t, t_{\operatorname{maxGRFz}}\right.$ and $\left.J_{\operatorname{maxGRF}}\right)$. The aforesaid values are easy to interpret on condition that the dancer can see the diagram (Fig. 1).

In the Authors' opinion, the most important variables which should be discussed with the performers are those directly visible in the diagram and usable in the feedback, i.e., $t, t_{\operatorname{maxGRFz}}$ and $\operatorname{maxGRF}_{\mathrm{z}}$ as well as, subsequently, the variables obtained indirectly from calculations, i.e., $L R_{\mathrm{GRF}}, J$, etc. The importance of the above-mentioned variables in safe amortization emerges from previous studies conducted on ballet dancers [12].
In the tests concerning Skip, in relation to all of the dancers in tests no. 2 and 3 , it was possible to observe a significant extension of $t$, restricted within the range of several to more than $90 \%$ in relation to the reference test (test no. 1). In relation to 3 dancers, the above-named increase amounted to above $30 \%$ in both tests with biofeedback. Also in relation to Sissone overt parallel, it was possible to observe the extension of $t$ in nearly each test with biofeedback. However, a change in the time of contact was smaller than that in relation to Skip (between several to a maximum of $45 \%$ ). Regarding Stag jump and Flat pas de chat, some measurements revealed the extension of $t$.

Regarding Skip, in relation to 3 dancers and test no. 2 , it was possible to observe the extension of $t_{\text {maxGRFz }}$. In relation to one of the dancers (D3), the aforesaid time was 2.5 times longer than that in the reference test (Table 4).

For as many as 4 dancers in one test with biofeedback during the performance of Sissone overt parallel, it was possible to observe the extension of time preceding the obtainment of the maximum value of the vertical component of the ground reaction force (up to 2.5 times). Regarding Stag jump, in relation to 4 dancers it was possible to record the extension of $t_{\operatorname{maxGRFz}}$ in the tests with biofeedback. In some cases, the extension of the above-named time was very significant, i.e., between 2 and as many as 10 times in comparison with test no. 1 . In nearly all measurements $(8$ in 10$)$ concerning Flat pas de chat with biofeedback, it was possible to observe the extension of $t_{\operatorname{maxGRF}}$. The time preceding the obtainment of $\operatorname{maxGRF}_{\mathrm{z}}$ was extended by between $10 \%$ and $166 \%$ in comparison with the reference test (Table 4).

Regarding Skip, in relation to 3 dancers it was possible to record a decrease in the maximum value of $\mathrm{GRF}_{\mathrm{z}}$ in both tests with biofeedback, and the decrease was restricted within the range of several to approximately $40 \%$.

Regarding Sissone overt parallel, only in relation to two dancers a decrease in the maximum values of $\mathrm{GRF}_{\mathrm{z}}$ restricted within the range of approximately $10 \%$ to $40 \%$, was recorded. In the cases of three dancers, it was possible to record an increase (!) in the value of $\operatorname{maxGRF}_{z}$, restricted within the range of several to $60 \%$ in relation to test no. 1 .

In relation to all of the dancers performing Stag jump, it was possible to record a decrease in the maximum value of $\mathrm{GRF}_{\mathrm{z}}$ restricted within the range of several to maximum $36 \%$ in comparison with the values recorded during the reference test.

Regarding Flat pas de chat, half of the measurements revealed a decrease, whereas half revealed an 
increase (!) value of $\operatorname{maxGRF} F_{\mathrm{z}}$. The maximum recorded decrease of the aforesaid value in relation to the reference measurement amounted to $43 \%$. In two cases, an increase in $\operatorname{maxGRF}_{z}$ was nearly double (Table 2).

Regarding all the dancers, in relation to Skip with biofeedback, it was possible to observe a decrease in loading rate $L R_{\mathrm{GRFz}}$. As regards the aforesaid evolution, the maximum recorded decrease in the value amounted to more than $80 \%$ in relation to the reference test.

Regarding Sissone overt parallel, in the cases of two dancers, it was possible to observe a decrease in the value of $L R_{\mathrm{GRFz}}$ in both tests with biofeedback (by a maximum of $70 \%$ ). In relation to three artists, it was possible to record an increase in $L R_{\mathrm{GRFz}}($ !). For all of the dancers in relation to Stag jump, it was possible to record a decrease in the value of $L R_{\mathrm{GRFz}}$ in tests no. 2 and 3 in comparison with the reference test; the maximum decrease was nearly two-fold. As regards Flat pas de chat, in relation to all of the dancers, in at least one test with biofeedback, it was possible to observe a decrease in $L R_{\mathrm{GRF}}$; the maximum decrease amounted to $70 \%$ in comparison with the value recorded in the reference test (Table 2).

An increase in the impulse of $\mathrm{GRF}_{\mathrm{z}}$ in the vertical direction during the entire stance phase was recorded in relation to 3 dancers performing Skip (a maximum increase of $50 \%$ ) and in relation to 4 dancers performing Sissone overt parallel (a maximum increase of $36 \%$ ).

Regarding Flat pas de chat, in relation to 3 dancers, it was possible to observe an over $10 \%$ increase in the impulse of $J$ in at least one test with biofeedback. In terms of Stag jump, in relation to 3 dancers, it was possible to observe a decrease in the impulse of $J$ (by a maximum of $30 \%$ ) and in relation to 2 dancers, it was possible to observe an increase of the aforesaid impulse value (by a maximum of approximately $40 \%$ ) in both tests with biofeedback (Table 3 ).

Interestingly, the change in the impulse of $\mathrm{GRF}_{z}$ in the vertical direction during the entire stance phase in the tests with biofeedback was similar in all of the dance evolutions subjected to analysis.

In most of the measurements with biofeedback in relation to Skip, it was possible to record a decrease in the impulse of the vertical component of GRF in the shock absorption phase $\left(J_{\operatorname{maxGRF}}\right)$; the decrease amounted to more than $30 \%$ if compared with the values determined in the reference test. In turn, in two measurements it was possible to record an over 2-fold increase in $J_{\text {maxGRFz. }}$ In relation to 4 soloists, it was possible to observe an increase in $J_{\text {maxGRFz }}$ in the tests with biofeedback concerning Sisonne overt parallel and Stag jump. In turn, regarding Flat pas de chat, in relation to all of the test participants, it was possible to notice an increase in $J_{\operatorname{maxGRF}}$ in at least one test with biofeedback (Table 3).

In general, according to the artists, movement classes of modern and contemporary dances, both during the professional career and in the preparation period, lead to overwork [9]. The dancers themselves stated that the movement exercises used in their profession weaken their ligamentous-muscular system instead of strengthening it and choreographers' visions are simply dangerous [9]. The Authors believe that the didactic laboratory session could constitute an attractive proposal and interesting experience enabling the development of one's own interpretation of safe landing based on an objective biomechanical method. It should also be mentioned that the artists' reaction to the training was very positive. The dancers treated the test as another challenge enabling them to improve their technique and self-control of the body. In addition, the experiment proposed by the Authors is relatively easy to perform in training. Usually, in the cities with dance theatres there are also university units with motion analysis laboratories. The advantage could be mutual - dancers could learn to minimise $G R F$, whereas researchers could acquire material for their research.

\subsection{Modern dancer's day at work}

In terms of biomechanics, the purpose of dance education is the obtainment of the maximum number of controllable degrees of freedom by the locomotor system. The above-named controllability is achieved within a long period of education, which, in Authors' opinion can be supported by biofeedback based on selected biomechanical methods. Soloists are known to be busier than members of corps de ballet [29] - their working day, including performances, classes and rehearsals, may last up to 10 hours [5], [15], [17], [19], [29], [32]. For this reason, training based on biomechanical methods must be well incorporated in an extremely tight schedule of modern dancers [5].

Work in a modern dance theatre is characterised by a specific rhythm of the day, week and of the entire year [5]. In most dance theatres the working day starts at $10.00 \mathrm{am}$. The so-called "midday" activities usually last until $2.00 \mathrm{pm}$. The first element of work during this part of the day is an appropriately prepared lesson of classical dance [18]. The purpose of the lesson is to gradually work out muscles of the body and perform the entire set of exercises improving the technique and precision of the dance and well as enhance dancer's 
condition, endurance and resistance to physical fatigue [26].

In accordance with the Russian school [30], a classical dance lesson usually lasts approximately 90 minutes and always has the same sequence. For 30 minutes the dancer exercises at the barre, starting with legs and gradually involving the head, arms and the torso. Afterwards, in the centre of the room, an hour is spent on exercises involving the performance of slow and unsupported phases of movements, i.e., the socalled "adagio" [18]. Next, artists make fast and precise jumps involving the complicated leg work, i.e., "petit allegro" [30]. The next stage includes great jumps - "grand allegro" [30]. Liederbach [23] counted that, during a "regular" lesson of classical dance, the dancer performs jumps more than 232 times. According to the Authors' observations, the maximum (peak) value of GRF during landing after a modern dance jump can be restricted within the range of $1.7 \mathrm{BW}$ to 5.47 BW. In the classical dance, the above-named force may reach as many as $11 \mathrm{BW}$ [15]. It is this moment (grand allegro) of the classical dance lesson, which could be continued individually by artists, using biofeedback supported by dynamometric platforms. There are many portable (mobile) platforms which could be placed in dance theatres. Similarly to the experiment discussed in the article, the effectiveness of the method could be increased by the application of the multimedia projector, presenting the course of GRF on a screen and, if need be, cameras recording movements performed by dancers (the correctness).

Afternoon activities last from approximately $6.00 \mathrm{pm}$ to $9.00 \mathrm{pm}$. On the days of ballet performances, artists start afternoon work at $5.00 \mathrm{pm}$, which is required within the preparation (make-up, hairstyling, putting on the costume and the workout of muscles of the entire body) of a performance starting at $7.00 \mathrm{pm}$ and finishing at $10.00 \mathrm{pm}$.

On "performance days", classes in the classical dance (exceptionally) take place a few hours before the performance. It is this time, i.e., the morning before performances, that could be used for the interpretation of GRF diagrams in relation to time. Dancers should be informed about the notion of "peak $\operatorname{maxGRF}_{\mathrm{z}}$ " and elements ensuring proper shock absorption.

\subsection{Practical suggestions for dancers about load reduction}

The extension of time between the moment in which the foot initially comes into contact with the ground and the moment when the heel is placed on the ground reduces the force of impact. The "flattening" of the "impact peak" in the GRF(t) diagram, i.e., the extension of time preceding the obtainment of $\operatorname{maxGRF}_{\mathrm{z}}$, makes landing gentler. In relation to the analysis of the diagram in Fig. 1, the value of the loading rate should be low.

To learn this new skill, artists should try to minimise impact forces on the platform repeatedly as the attempts to reduce impact force do not always finish successfully. To have a "better feel" (and control) of effective shock absorption, dancers should be subjected to such training successively.

An increase in the impulse of $J$ related to BW reduces impact force. An increase in $J_{\operatorname{maxGRFz}}$ results from the extension of time preceding the obtainment of $\operatorname{maxGRF} F_{z}$.

\subsection{Summary}

Medilian et al. [24] proposed that science and art should cooperate on stage to create a cohesive element. The Authors suggest that science should enter dance training halls or/and art should enter motion analysis laboratories, to optimise dancer's training. The selection of modern dance resulted from the fact that, unlike classical dance, this style provides the artist with a significant margin of their own interpretation. Although the research was concerned with masters (soloists), it seems justifiable to propose training also at lower levels of education, i.e., in ballet schools or universities, and make it part of the artist's extremely busy working day. In addition, the method enabling the minimisation of impact forces can also be applied in other styles of dance, e.g., classical dance, folk dance, flamenco [10], etc.

\subsection{Limitations}

The Authors realise that the number of test participants was low. However, modern dance theatres do not have such high employment as classical dance ones. The invitation of five outstanding artists (meeting the criteria of first soloists) to participate in the experiment appeared difficult. However, the conducted pilot studies allowed for the calculation of the minimum sample size to detect significant differences in reducing maxGRF, and a group of such size was tested. Even so, it should be remembered that a low simple size has an influence on the probability of Type II errors. The test power changes in the same direction 
as the sample size, i.e., as the sample size increases, the test power increases. The power of the test changes inversely to the changes in the value of the type II error $(\beta)$. A low sample size increases the probability of a Type II error. As a general principle, small sample size does not increase the Type I error $(\alpha)$ rate, because the test is arranged to control the Type I rate.

\section{Conclusions}

Biofeedback in the form of information about the value of the vertical component of the ground reaction force and the visualisation of the $\mathrm{GRF}_{z}$ course in relation to the artist's body weight may result in the change of the post-jump shock absorption technique in relation to dance evolutions analysed in the above-presented research. The foregoing should lead to:

- extension of contact time and of time preceding the obtainment of maxGRF $F_{z}$ - these times can be extended by more than twice,

- reduction of the maximum values of the vertical components of the ground reaction force - in the group subjected to analysis, it was possible to observe a decrease in $\operatorname{maxGRF}_{z}$ by more than $40 \%$,

- reduction of the loading rate of the ground reaction force $L R_{\mathrm{GRFz}}$ (by twice),

- increase in the impulse of the vertical component of GRF during the entire stance phase $J$ and an increase of the impulse in the shock absorption phase $J_{\operatorname{maxGRFz}}$, primarily resulting from extension of contact time and time preceding the obtainment of $\operatorname{maxGRF} F_{z}$.

It appeared that even masters of technique required several attempts to acquire the skill enabling the reduction of $\mathrm{GRF}_{\mathrm{z}}$; not all attempts undertaken to reduce $\mathrm{GRF}_{\mathrm{z}}$ were successful.

In order to learn safe landing after a jump, a didactic laboratory session should be organized using a method of measuring the vertical component of the ground reaction. It should be noted that the advantage of this experiment is its simplicity, i.e., the use of one measurement method and the analysis of one GRF component.

The above-presented instructions based on the results obtained in the experimental tests indicate that the implementation of the minimising training discussed in the article can lead to the reduction of loads exerted on the musculoskeletal system.

\section{Acknowledgements}

We thank Jacek Mączyński, MSc (Department of Biomechanics, Chair of Theory and Methodology of Sport, Faculty of Sport Science, Poznan University of Physical Education, Poznań, Poland) for help in carrying out measurements.

\section{Funding}

This work was conducted within the grant NN404515938 supported by the Polish Ministry of Science and Higher Education and supported within the project "Biomechanical studies of biological systems and processes”, project no. 07/030/BK_21/2054.

\section{References}

[1] Ahonen J., Biomechanics of the foot in dance: A literature review, J. Dance. Med. Sci., 2008, 12 (3), 99-108, PMID: 19618585.

[2] Ambegaonkar J.P., Caswell S.V., Development and implementation of an in-house healthcare program for university-level performing artists, Work, 2011, 40 (3), 261-268, DOI: 10.3233/WOR-2011-1228.

[3] Angioi M., Metsios G., Twitchett E.A., Koutedakis Y., Wyon M.A., Effects of Supplemental Training on Fitness and Aesthetic Competence Parameters in Contemporary Dance. A Randomised Controlled Trial, Med. Probl. Perform. Art., 2012, 27 (1), 3-8, DOI: 10.21091/mppa.2012.1002.

[4] Angioi M., Metsios G.S., Koutedakis Y., Twitchett E., WyOn M.A., Physical fitness and severity of injuries in contemporary dance, Med. Probl. Perform. Art., 2009, 24 (1), 26.

[5] Bronner S., Wood L., Impact of touring, performance schedule, and definitions on 1-year injury rates in a modern dance company, J. Sport. Sci., 2016, 35 (21), 2093-2104, DOI: 10.1080/02640414.2016.1255772.

[6] BRONNER S., BAUER N.G., Risk factors for musculoskeletal injury in elite pre-professional modern dancers: A prospective cohort prognostic study, Phys. Ther. Sport, 2018, 18 (31), 42-51, DOI: 10.1016/j.ptsp.2018.01.008.

[7] Bronner S., Ojofeitimi S., Rose D., Injuries in a modern dance company. Effects of comprehensive management on injury incidence and time loss, Am. J. Sport. Med., 2003, 31, 365-373, DOI: $10.1177 / 03635465030310030701$.

[8] De LeONARDis M., Greco G., Effects of a plyometric supplemental training on vertical jump height and aesthetic jumping ability in adolescent female dancers, Eur. J. Phys. Educ. Sport Sci., 2020, 6 (2), 49-62, DOI: 10.5281/zenodo.3692663.

[9] Evans B., How I survived my dance training: rhythm, tap, and modern dance, Med. Probl. Perform. Art., 2003, 18 (4), 137.

[10] ForCZEK-KARKoSZ W., MichniK R., NOWAKOWSKA-LiPIEC K., Vargas-Macias A., BaEnA-Chicón I., Gómez-Lozano S., GoRwA J., Biomechanical description of Zapateado technique in flamenco, Int. J. Env. Res. Pub. He., 2021, 18, 2905, DOI: 10.3390/ijerph18062905.

[11] Fuhrmann T., Brayer A., Andrus N., McIntosh S., Injury Prevention for Modern Dancers: A Pilot Study of an Educational Intervention, J. Commun. Health, 2010, 35, 527-533, DOI: $10.1007 / \mathrm{s} 10900-010-9223-\mathrm{z}$. 
[12] Gorwa J., Fryzowicz A., Michnik R., JurkojĆ J., KABACIŃSKI J., JOCHYMCZYK-WoŹNIAK K., DWORAK L., Can we learn from professional dancers safe landing? Kinematic and dynamic analysis of the 'grand pas de chat' performed by female and male dancer, [In:] M. Gzik, E.Tkacz, Z. Paszenda, E. Piętka (Eds.), Advances in Intelligent System and Computing, Cham: Springer International Publishing, 2019, 233-240, DOI: 10.1007/978-3-030-15472-1_25.

[13] Gorwa J., Kabaciński J., Murawa M., Fryzowicz A., On the track of the ideal turnout: Electromyographic and kinematic analysis of the five classical ballet positions, PLOS ONE, 2020, DOI: 10.1371/journal.pone.0230654.

[14] Gorwa J., Kabaciński J., Murawa M., Fryzowicz A., Which of the five classical ballet positions is the most demanding for the dancer's body? An electromyography-based study to determine muscular activity, Acta Bioeng. Biomech., 2020, 22 (4), 3-14, DOI: 10.37190/ABB-01650-2020-02.

[15] Gorwa J., Michnik R., Nowakowska-LiPIEC K., In pursuit of the perfect dancer's ballet foot. The footprint, stabilometric, pedobarographic parameters of professional ballet dancers, Biology, 2021, 10 (5), 435, DOI: 10.3390/ biology 10050435 .

[16] GORWA J., MichNIK R.A., NOWAKOWSKA-LIPIEC K., JURKOJĆ J., JOCHYMCZYK-WOŹNIAK K., Is it possible to reduce loads of the locomotor system during the landing phase of dance figures? Biomechanical analysis of the landing phase in Grand Jeté, Entrelacé and Ballonné, Acta Bioeng. Biomech., 2019, 21 (4), 111-121, DOI: 10.5277/ABB-01429-2019-02.

[17] Gorwa J., Zieliński J., WOlańSKi W., Michnik R.A., LARYSZ D., DWORAK L.B., Kusy K., Decreased bone mineral density in forearm vs loaded skeletal sites in professional ballet dancers, Med. Probl. Perform. Art., 2019, 34 (1), 25-32, DOI: $10.21091 / \mathrm{mppa} .2019 .1006$.

[18] Guidetti L., Gallotta M.C., Emerenziani G.P., Baldari C., Exercise intensities during a ballet lesson in female adolescents with different technical ability, Int. J. Sports Med., 2007, 28 (9), 736-742, DOI: 10.1055/s 2007-964909.

[19] Haight H.J., Morphologic, physiologic, and functional interactions in elite female ballet dancers, Med. Probl. Perform. Art., 1998, 3, 4-13.

[20] Kalaycioglu T., Apostolopoulos N., Goldere S., Duger T., BALTACI G., Effect of a core stabilization training program on performance of ballet and modern dancers, J. Strength Cond. Res., 2020, 34 (4), 1166-1175, DOI: 10.1519/ JSC.0000000000002916.

[21] LEGG J., Introduction to modern dance techniques, 2011, ISBN-13: 978-0871273253. Princeton Book Company.
[22] Liederbach M., Dilgen F.E., Rose D.J., Incidence of anterior cruciate ligament injuries among elite ballet and modern dancers injuries in a modern dance company, Am. J. Sports Med., 2008, 36 (8), 1779-1788, DOI: 10.1177/ 0363546508323644.

[23] Liederbach M., Richardson M., Rodriguez M., Compagno J., Dilgen F.E., Rose D.J., Jump exposures in the dance training environment: a measure of ergonomic demand, J. Athl. Training, 2006, 41, S85.

[24] Medilian L., Diefenbach P., Kim Y., Information overload: A collaborative dance performance, IEEE Multimedia, 2010, 17 (1), 8-13, DOI: 10.1109/MMUL.2010.15.

[25] OJOFEITIMI S., BRONNER S., Injuries in a modern dance company effect of comprehensive management on injury incidence and cost, J. Dance Med. Sci., 2011, 15 (3), 116-122, PMID: 22040757.

[26] Rodrigues-Krause J., Krause M., ReischaK-Oliveira A., Cardiorespiratory considerations in dance: from classes to performances, J. Dance Med. Sci., 2015, 19 (3), 91-102, DOI: $10.12678 / 1089-313 X .19 .3 .91$.

[27] Steinberg N., Siev-Ner I., Peleg S., Dar D., Masharawi Y., ZeEv A., HershKovitz I., Extrinsic and intrinsic risk factors associated with injuries in young dancers aged 8-16 years, J. Sport. Sci., 2012, 30, 485e495, DOI: 10.1080/ 02640414.2011 .647705$.

[28] Tekin D., Agopyan A., Baltaci G., Balance training in modern dancers: proprioceptive-neuromuscular training vs kinesio taping, Med. Probl. Perform. Art., 2018, 33 (3), 156-165, DOI: 10.21091/mppa.2018.3022.

[29] Twitchett E., Angioi M., Koutedakis Y., Wyon M., The demands of a working day among female professional ballet dancers, J. Sport. Sci., 2010, 14 (4), 127-32, PMID: 21703083.

[30] Vaganova A., Basic principles of classical ballet. Russian ballet technique, Chapter 1, 4th ed., Dover Publications, Inc., New York, 2015.

[31] WeIGERT B., ERICKSON K., Incidence of injuries in Female University - Level modern dancers and the effectiveness of a screening program in altering injury patterns, Med. Probl. Perform. Art., 2007, 22 (2), 52.

[32] Weiss D.S., Shah S., Burchette R.J., A profile of the demographics and training characteristics of professional modern dancers, J. Dance Med. Sci., 2008, 12 (2), 41-6, PMID: 19618577.

[33] WinIARSKI S., RUTKOWSKA-KUCHARSKA A., Estimated ground reaction force in normal and pathological gait, Acta Bioeng. Biomech., 2009, 11 (1), 53-60, PMID: 19739592. 